\title{
Safety and Efficacy of Filgotinib: Up to 4-year Results From an Open-label Extension Study of Phase II Rheumatoid Arthritis Programs
}

\author{
Arthur Kavanaugh ${ }^{1}$, Rene R. Westhovens ${ }^{2}$, Kevin L. Winthrop ${ }^{3}$, Susan J. Lee ${ }^{4}$, YingMeei Tan ${ }^{4}$, \\ Di An ${ }^{4}$, Lei Ye ${ }^{4}$, John S. Sundy ${ }^{4}$, Robin Besuyen ${ }^{5}$ (D), Luc Meuleners5 ${ }^{5}$, Mykola Stanislavchuk ${ }^{6}$, \\ Alberto J. Spindler ${ }^{7}$, Maria Greenwald ${ }^{8}$, Rieke Alten ${ }^{9}$ iD, and Mark C. Genovese ${ }^{10}$ (D)
}

\begin{abstract}
Objective. The long-term safety and efficacy of filgotinib (from phase II studies), with or without methotrexate (MTX), for the treatment of patients with rheumatoid arthritis was assessed in DARWIN 3, a longterm, open-label extension study (ClinicalTrials.gov: NCT02065700).

Methods. Eligible patients completing the 24-week DARWIN 1 (filgotinib + MTX) and DARWIN 2 (filgotinib monotherapy) studies entered DARWIN 3, where they received filgotinib $200 \mathrm{mg} /$ day, except for 15 men who received filgotinib $100 \mathrm{mg}$ /day. Safety analyses were performed using the safety analysis set and the exposure-adjusted incidence rate (EAIR) of treatment-emergent adverse events (TEAEs) was calculated. Efficacy was assessed from baseline in the parent studies.

Results. Of 790 patients completing the phase II parent studies, 739 enrolled in the study. Through April $2019,59.5 \%$ of patients had received $\geq 4$ years of the study drug. Mean (SD) exposure to filgotinib was 3.55 (1.57) years in the filgotinib + MTX group and 3.38 (1.59) years in the filgotinib monotherapy group. EAIR per 100 patient-years of exposure for TEAEs was 24.6 in the filgotinib + MTX group and 25.8 in the filgotinib monotherapy group, and for serious TEAEs, the EAIR was 3.1 and 4.3, respectively. American College of Rheumatology 20/50/70 responses among patients remaining in the study could be maintained through 4 years, with $89.3 \% / 69.6 \% / 49.1 \%$ of the filgotinib + MTX group and $91.8 \% / 69.4 \% / 44.4 \%$ of the monotherapy group maintaining ACR20/50/70 responses, respectively, based on observed data.

Conclusion. Filgotinib was well tolerated with a 4-year safety profile comparable to that of the parent trials, both in patients receiving combination therapy with MTX or as monotherapy.
\end{abstract}

Key Indexing Terms: ACR improvement criteria, inflammation, methotrexate, rheumatoid arthritis

Rheumatoid arthritis (RA) is a chronic, systemic autoimmune disease characterized by persistent joint inflammation, and if insufficiently treated, may lead to loss of joint function, disability, and decreased quality of life. The aim of RA treatment is to achieve persistent remission or low disease activity by inhibiting inflammation and preventing joint damage and disability. ${ }^{1,2}$
Conventional synthetic and biologic disease-modifying antirheumatic drugs (csDMARDs and bDMARDs) used to treat RA may have limitations for some patients, including slow and incomplete responses, loss of efficacy over time, and/or side effects. ${ }^{3,4}$ Inhibition of the Janus kinase (JAK) pathway, which blocks intracellular signaling of cytokine pathways implicated in
This study was funded by Gilead Sciences Inc.

${ }^{1}$ A. Kavanaugh, MD, University of California San Diego, La Jolla, California, USA; ${ }^{2}$ R.R. Westhovens, MD, PhD, KU Leuven, Skeletal Biology and Engineering Research Center, Leuven, Belgium; ${ }^{3}$ K.L. Winthrop, MD, MPH, Oregon Health and Science University, Portland, Oregon, USA; ${ }^{4}$ S.J. Lee, MD, Y. Tan, PhD, D. An, PhD, L. Ye, PhD, J.S. Sundy, MD, PhD, Gilead Sciences Inc., Foster City, California, USA; ${ }^{5} R$. Besuyen, MD, L. Meuleners, MS, Galapagos NV, Mechelen, Belgium; ${ }^{6}$ M. Stanislavchuk, MD, National Pirogov Memorial Medical University, Vinnytsya, Ukraine; ${ }^{7}$ A.J. Spindler, MD, Centro Medico Privado de Reumatologia, San Miguel de Tucuman, Argentina; ${ }^{8} M$. Greenwald, MD, Desert Medical Advances, Palm Desert, California, USA; ${ }^{9}$. Alten, MD, Schlosspark Klinik, University Medicine Berlin, Berlin, Germany; ${ }^{10}$ M.C. Genovese, MD, Stanford University School of Medicine, Division of Immunology \& Rheumatology, Stanford, and Gilead Sciences Inc., Foster City, California, USA.
$A K$ has received consulting fees from Gilead Sciences Inc. $R W$ has received consulting fees from Celltrion, Galapagos, Gilead Sciences Inc., Bristol Myers $S q u i b b$, and Roche. KW has received consulting fees from Gilead Sciences Inc., Galapagos, AbbVie, Eli Lilly, and Pfizer. SL, YT, DA, LY, and JS are employees of Gilead Sciences Inc. RB and LM are employees of Galapagos NV. $M G$ has received consulting fees from Celgene, Bristol Myers Squibb, Gilead Sciences Inc., Eli Lilly, Pfizer, AbbVie, Fuji, and Novartis. RA has received consulting fees from Gilead Sciences Inc. and Galapagos. MG has received consulting fees from Galapagos, AbbVie, Eli Lilly, Pfizer, and Gilead Sciences Inc. MS and AS report no disclosures.

Address correspondence to Prof. A. Kavanaugh, Center for Innovative Therapy, Division of Rheumatology, Allergy \& Immunology, University of California San Diego School of Medicine 9500 Gilman Drive, \#0943, La Jolla, CA 92093,USA.Email: akavanaugh@ucsd.edu.

Accepted for publication January 14, 2021. 
RA pathogenesis, has been shown to be effective in patients with RA. Three JAK inhibitors are approved globally for the treatment of RA: tofacitinib, baricitinib, and upadacitinib. $5.6,7,8,9,10$

Filgotinib, an orally administered, preferential JAK1 inhibitor, is approved in the European Union and Japan for the treatment of RA and is currently under investigation for other chronic inflammatory diseases. In 2 prior phase IIb studies, filgotinib, in combination with methotrexate (MTX) and as monotherapy, ${ }^{11,12}$ was shown to be effective in treating RA. The DARWIN 3 study (ClinicalTrials.gov: NCT02065700) is an ongoing, open-label, long-term extension (LTE) study of the phase IIb parent studies evaluating the long-term safety and tolerability of filgotinib. Safety and efficacy data through 4 years are presented here.

\section{METHODS}

Studypatients. Patients rolled over to the LTE included $84.3 \%$ of patients who were treated and $93.5 \%$ who completed the 24 -week parent studies. Patients from DARWIN 1 were aged $\geq 18$ years with a diagnosis of RA according to the 2010 American College of Rheumatology (ACR)/European League Against Rheumatism criteria for $\geq 6$ months. They were ACR functional class I-III with $\geq 6$ of swollen joint count in 66 joints, $\geq 8$ of tender joint count in 68 joints, $\mathrm{C}$-reactive protein $(\mathrm{CRP}) \geq 0.7$ times the upper limit of normal (ULN); and were taking MTX for $\geq 6$ months and corticosteroids $\leq 10 \mathrm{mg} /$ day at stable doses for $\geq 4$ weeks prior to screening. Patients with a prior history of bDMARD treatment and/or taking csDMARDs other than MTX were excluded. ${ }^{12}$ Eligibility criteria for patients from DARWIN 2 were similar, with the exceptions of higher screening CRP $(\geq 1.2 \times \mathrm{ULN})$, allowance of antimalarials, and required MTX washout. ${ }^{11}$

Study design. Patients in DARWIN 1 were randomized to placebo or filgotinib (total 50-200 mg/day, given either once or twice daily) plus MTX (15-25 mg/week). ${ }^{12}$ In DARWIN 2, patients were randomized to placebo or filgotinib monotherapy $\left(50,100\right.$, or $200 \mathrm{mg}$ daily).${ }^{11}$ Patients were allowed to start or stop MTX during LTE according to the investigator's judgment. All patients enrolled in the LTE received filgotinib $200 \mathrm{mg}$, either as $200 \mathrm{mg}$ daily or $100 \mathrm{mg}$ twice daily, except for $15 \mathrm{men}$ in the United States who received $100 \mathrm{mg}$ daily due to a requirement by the U.S. Food and Drug Administration (7 analyzed as filgotinib + MTX and 8 as filgotinib monotherapy). Dose adjustment between $100 \mathrm{mg}$ and $200 \mathrm{mg}$ daily was allowed for safety/tolerability issues. The study was conducted in accordance with ethical principles of the Declaration of Helsinki and Good Clinical Practice guidelines, and was approved by our US central institutional review board (approval no. INC1-14-016). Patients provided written informed consent to participate in the study and had the right to withdraw at any time.

Assessments. Safety variables included all events that occurred after patients received their first dose of filgotinib (in either the parent or LTE study). Safety assessments included monitoring of adverse events (AEs) and laboratory abnormalities according to National Institutes of Health Common Terminology Criteria for Adverse Events (CTCAE) 4.03 toxicity grade. Major adverse cardiac events (MACE; defined as cardiovascular [CV] death, myocardial infarction, stroke) and thromboembolic events were adjudicated by an independent committee. For AEs, relatedness to study drug was assessed by the investigator. Annual tuberculosis (TB) testing was performed using the 3-tube QuantiFERON-TB Gold assay in the parent studies; in the LTE study, a newer, more sensitive 4-tube QuantiFERON-TB Gold Plus assay was utilized. All newly positive TB tests resulted in study exit until March 2018, at which time patients with latent TB could remain in the study with appropriate latent TB treatment initiation and completion.

Efficacy was measured as the change from baseline in the parent studies and assessed every 12 weeks, except for Functional Assessment of Chronic Illness Therapy Fatigue scale and 36-item Short Form health survey questionnaires.
Statistical analyses. Patients were grouped as filgotinib + MTX and filgotinib monotherapy based on their parent study designation. There were 22 patients from DARWIN 2 who started MTX and 1 patient from DARWIN 1 who did not receive MTX in the LTE. The analysis included all data from the parent studies through April 26, 2019, when all remaining patients $(53.3 \%$ and $56.2 \%$ in the filgotinib + MTX and filgotinib monotherapy groups, respectively) had at least 4 years of filgotinib exposure (Supplementary Figure 1, available with the online version of this article). The safety analysis included all patients who received at least 1 dose of study drug. Treatment-emergent AEs (TEAEs) were defined as an AE that occurred on or after the first dose of filgotinib, up to 30 days after the last dose. Exposure-adjusted incidence rates (EAIRs) for TEAEs were calculated as total number of patients with the specific event divided by total patient-years of exposure (PYE) to filgotinib. Laboratory assessments were performed every 12 weeks. Changes in laboratory values were derived relative to the date of the first dose of filgotinib in either the parent studies or LTE. Treatment-emergent laboratory abnormalities were defined as values that increased by $\geq 1$ toxicity grade from baseline at any postbaseline timepoint, up to the last dose of filgotinib plus 30 days.

Efficacy analyses included all patients who received $\geq 1$ dose of study drug. For the analysis using observed cases (OC), missing data were not imputed. For the analysis using nonresponder imputation (NRI), missing data were imputed as nonresponder. For binary endpoints, both OC and NRI data were summarized using descriptive statistics (counts and proportions of patients) by treatment and visit. For continuous endpoints, the change scores were derived relative to the baseline value collected on the first dose date of any study drug in the parent studies.

\section{RESULTS}

Demographics/baseline characteristics. A total of 739 patients at 114 centers in 22 countries were enrolled in the LTE. A summary of demographics and baseline characteristics at the start of the parent studies is shown in Table 1 . The majority of patients were female $(81.5 \%, 81.8 \%)$ and White $(75.3 \%, 74.8 \%)$, with a mean age of 53 and 52 years, in the filgotinib + MTX and filgotinib monotherapy groups, respectively. The mean MTX dose in the filgotinib + MTX group remained stable from the parent to LTE baseline (16.8-16.9 mg/week). At the LTE baseline, a majority were taking oral MTX ( $82.8 \%$ oral vs $17.2 \%$ other). Approximately half of the patients were on corticosteroids at the parent and LTE baseline with a mean dose of $6.1 \mathrm{mg} /$ day in the LTE.

The total PYE to filgotinib was 2582 with mean \pm SD exposure of $3.55 \pm 1.57$ years in the filgotinib + MTX group and 3.38 \pm 1.59 years in the filgotinib monotherapy group with maximum exposure of 5.6 years (293.4 weeks) and 5.4 years (280.6 weeks), respectively. At the time of this analysis, 440 (59.5\%) patients had received $\geq 4$ years of filgotinib with 401 (54.3\%) patients still remaining in the study. A total of $338(45.7 \%)$ patients discontinued treatment prematurely: 232 (46.7\%) in the filgotinib + MTX group and 106 (43.8\%) in the filgotinib monotherapy group. The majority of patients who discontinued treatment prematurely $(\mathrm{n}=299,88.5 \%)$ had $<4$ years of filgotinib exposure (Figure 1; Supplementary Figure 1, available with the online version of this article). The most common reasons for discontinuation were AEs ( $n=212,28.7 \%$, with latent TB/ positive TB test accounting for $46.7 \%$ of the 212 patients) and patient requests $(\mathrm{n}=78,10.6 \%)$. All but 12 discontinuations due to latent TB were protocol mandated prior to the protocol 
Table 1. Demographics and baseline characteristics (all data represent characteristics at entry into the parent studies).

Filgotinib + MTX, Filgotinib Monotherapy, Total,

$\mathrm{n}=497 \quad \mathrm{n}=242 \quad \mathrm{n}=739$

Demographics at parent study baseline

Age, yrs

Female

$53 \pm 11.7$

$52 \pm 12.2$

$53 \pm 11.9$

Race

White

405 (81.5)

$198(81.8)$

603 (81.6)

Other

$374(75.3)$

$119(23.9)$

$181(74.8)$

$555(75.1)$

Black or African American

$3(0.6)$

Asian

$1(0.2)$

$56(23.1)$

$175(23.7)$

Native Hawaiian or Pacific Islander

0

$3(1.2)$

$6(0.8)$

$1(0.4)$

$2(0.3)$

$28.3 \pm 5.74$

$1(0.4)$

$1(0.1)$

BMI, $\mathrm{kg} / \mathrm{m}^{2}$

Geographic region

Latin America

$186(37.4)$

$27.6 \pm 5.55$

$28.1 \pm 5.69$

Central and Eastern Europe, EU

$136(27.4)$

$75(31.0)$

$261(35.3)$

Central and Eastern Europe, non-EU

West and Asia Pacific

$79(15.9)$

$53(21.9)$

$189(25.6)$

$96(19.3)$

$73(30.2)$

$152(20.6)$

Disease characteristics at parent study baseline

$41(16.9)$

$137(18.5)$

Duration of RA from diagnosis, $\mathrm{yrs}^{\mathrm{a}}$

RF-positive

$8.3 \pm 7.1$

Anti-CCP-positive

Prior exposure to bDMARD ${ }^{\mathrm{b}}$

Concurrent corticosteroids on first dosing date

Concurrent MTX dose on first dosing date,

$\mathrm{mg} / \mathrm{mL}$

$382(76.9)$

$402(80.9)$

$48(9.7)$

$239(48.1)$

$8.9 \pm 7.1$

$8.5 \pm 7.1$

$180(74.4)$

$192(79.3)$

$19(7.9)$

$562(76.0)$

$594(80.4)$

$143(59.1)$

$67(9.1)$

$382(51.7)$

$16.8 \pm 4.2$

NA

$16.8 \pm 4.2$

Values are expressed as $\mathrm{n}(\%)$ or mean \pm SD. ${ }^{\mathrm{a}}$ Duration of RA (yrs) $=$ (first dose date in core studies - date of initial diagnosis +1$) / 365.25 .{ }^{b}$ Patients were excluded from the parent studies if they had previous RA treatment with a bDMARD. The only exception to this was if the biologic agent had been received in a single clinical study $>6$ months prior to enrollment and if the drug had been effective. BDMARD: biologic disease-modifying antirheumatic drug; CCP: cyclic citrullinated peptide; EU: European Union; MTX: methotrexate; NA: not applicable; RA: rheumatoid arthritis; RF: rheumatoid factor.

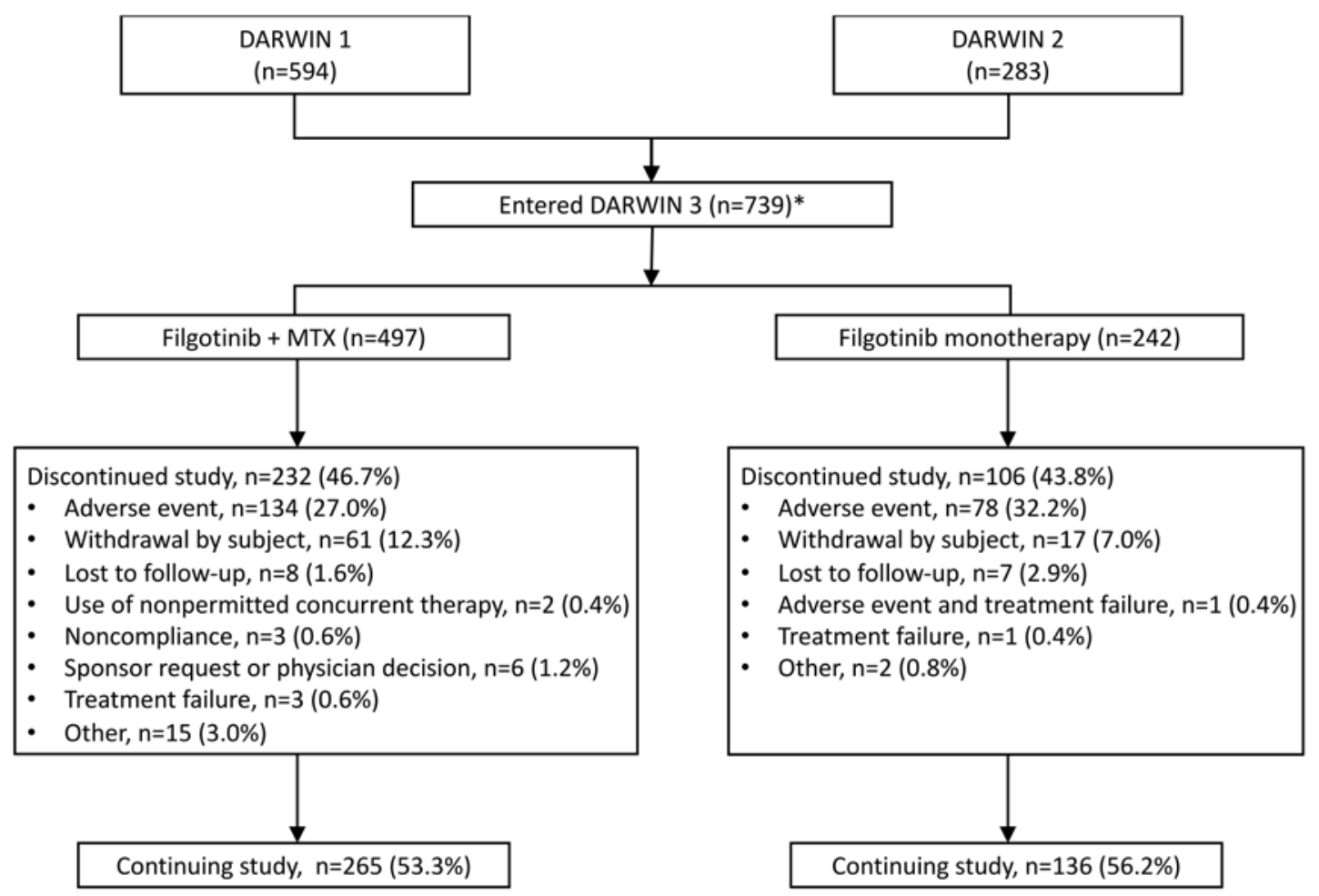

Figure 1. Patient disposition (April 26, 2019). * Patients were assigned to filgotinib + MTX or filgotinib monotherapy groups based on their parent study designation. Patients from DARWIN 1 were analyzed as filgotinib + MTX and patients from DARWIN 2 as filgotinib monotherapy. MTX: methotrexate. 
amendment in March 2018. No active TB cases were reported by the investigators among patients who exited with a newly positive test. Dose reductions occurred in 31 patients due to AEs/ intolerance $(n=24)$ or unknown reasons $(n=8)$, of which 11 increased back to $200 \mathrm{mg}$ (Supplementary Table 1).

AEs. The number of TEAEs and EAIRs per 100 PYE are shown in Table 2. A total of 434 (EAIR 24.6) patients in the filgotinib + MTX group and 211 (EAIR 25.8) in the filgotinib monotherapy group experienced TEAEs, of which nearly half were considered treatment-related. Most TEAEs were mild or moderate in severity. The EAIRs for TEAEs that led to study discontinuation were 7.4 and 9.4 in the filgotinib + MTX and filgotinib monotherapy groups, respectively (Table 2).

Six deaths (3 in each group) occurred during the study, of which 4 were reported as study drug related ( 1 due to meningococcal meningitis, 2 due to non-Hodgkin lymphomas [NHL], and 1 due to pneumonia). The remaining deaths were due to 1 case of simultaneous deep vein thrombosis (DVT) and pulmonary embolism (PE) occurring > 30 days after the last filgotinib dose, and 1 case of metastatic leiomyosarcoma of cutaneous origin occurring 15 days after the last filgotinib dose.

Infectious and serious infectious AEs. The EAIRs for any infectious AEs were 16.3 and 15.9 in the filgotinib + MTX and filgotinib monotherapy groups, respectively. Twenty-four (EAIR 1.4) patients in the filgotinib + MTX and 16 (EAIR 2.0) in the filgotinib monotherapy group discontinued filgotinib due to infectious TEAEs. Most infectious TEAEs were mild or moderate in severity. The EAIRs for any serious infectious AEs were 0.6 and 1.7 in the filgotinib + MTX and filgotinib monotherapy groups, respectively (Table 2 ). The EAIRs for both infection categories were similar in patients with and without leukopenia (Supplementary Figure 2, available with the online version of this article). There were no cases of active TB. Twelve patients with latent $\mathrm{TB}$ who remained in the study received isoniazid for 3-10 months or a combination of rifampin and isoniazid for 3 months.

Herpes zoster virus infections. The EAIRs for herpes zoster virus $(\mathrm{HZV})$ infections were 1.3 and 1.5 in the filgotinib + MTX and filgotinib monotherapy groups, respectively (Table 2). Except for 1 serious ophthalmic HZV case, all HZV infections were cutaneous, and mild or moderate in severity. Of 35 patients with HZV infections, 13 temporarily interrupted filgotinib, 6 exited the study, and 16 continued with filgotinib. One patient in the filgotinib + MTX group had a recurrent HZV infection; treatment was interrupted during the first event and discontinued after the second event. All but 5 patients were treated with antivirals. The EAIR of HZV infection was similar in patients with and without lymphopenia (defined as grade $\geq 1$ per CTCAE definition). Four patients experienced lymphopenia (grade 1-2) within 30 days of HZV diagnosis (2 on corticosteroid doses of 4.0 and $7.5 \mathrm{mg} / \mathrm{d}$ prednisone, both on MTX) and 12 patients $>30$ days from infection (Supplementary Figure 2, available with the online version of this article).

Malignancies. Malignancies were reported among 9 (EAIR 0.5) patients in the filgotinib + MTX and 5 (EAIR 0.6) in the filgotinib monotherapy group, excluding nonmelanoma skin cancer (NMSC). Six (EAIR 0.3) patients in the filgotinib + MTX and 1 (EAIR 0.1) in the filgotinib monotherapy group had NMSC (Table 2). Thirteen patients had treatment-emergent malignancies: 4 hematologic (3 NHL, 1 diffuse large B-cell lymphoma) and 9 solid tumors. One case of NHL was considered related to study drug.

Gastrointestinal perforation. One patient (EAIR 0.1) in the filgotinib + MTX group experienced a small bowel perforation during hysterectomy for uterine adenomyosis.

$D V T / P E$. One patient with a recent foot infection (EAIR 0.1) in the filgotinib + MTX group, previously captured under "death" experienced DVT and PE simultaneously (Table 2).

$M A C E$. There was $1 \mathrm{CV}$ death from DVT/PE and 4 nonfatal cases of stroke. All patients who experienced a stroke had $\geq 1 \mathrm{CV}$ risk factor (hypertension, coronary artery disease). The EAIR was 0.2 for both groups; these events were considered not related to the study drug (Table 2).

Laboratory variables. The majority of laboratory abnormalities were grade 1 or 2 TEAEs (Table 3; Supplementary Table 2, available with the online version of this article). Mean values at baseline (first dose of filgotinib in parent study or LTE) and at Week 204, along with details of patients experiencing shifts to grade $\geq 3$ through Week 204 are listed in the sections that follow.

Anemia. Mean (SD) hemoglobin ( $\mathrm{Hb} ; \mathrm{g} / \mathrm{dL})$ values were 12.7 (1.4) and 12.8 (1.5) at baseline, and 13.7 (1.5) and 13.6 (1.4) at Week 204 in the filgotinib + MTX and filgotinib monotherapy groups, respectively. Five patients with normal $\mathrm{Hb}$ or mild anemia at baseline experienced severe anemia through Week 204 ( 3 in the filgotinib + MTX group; 2 resolved without intervention, 3 discontinued from the study).

Neutropenia. Mean (SD) neutrophil counts $\left(\times 10^{3} / \mu \mathrm{L}\right)$ were 6.1 (2.5) and 6.4 (2.5) at baseline, and 4.3 (1.7) and 4.2 (1.6) at Week 204 in the filgotinib + MTX and filgotinib monotherapy groups, respectively. Three patients had an increase in severity to grade 3 through Week 204; all resolved without intervention. Two patients had an increase from grade 0 to grade 4; 1 resolved after temporary interruption of filgotinib and filgotinib was resumed without recurrence, and 1 discontinued from the study. Lymphopenia. Mean (SD) lymphocyte counts $\left(\times 10^{3} / \mu \mathrm{L}\right)$ were $1.9(0.7)$ and $2.1(0.8)$ at baseline, and $1.5(0.6)$ and $1.5(0.5)$ at Week 204 in the filgotinib + MTX and filgotinib monotherapy groups, respectively. Sixteen patients had an increase in severity to grade 3 through Week 204 ( 8 normalized on repeat assessment without any change in MTX or filgotinib dose, 3 had concurrent infections and/or started antibiotics at the time of lymphopenia, 4 exited the study, and 1 continued to fluctuate throughout the study). One patient with an increase to grade 4 remained in the study with continued grade 0-3 fluctuation.

Thrombocytopenia. Mean (SD) platelet counts $\left(\times 10^{3} / \mu \mathrm{L}\right)$ were 321 (95) and $314(88)$ at baseline, and 278 (72) and 275 (74) at Week 204 in the filgotinib + MTX and filgotinib monotherapy groups, respectively. One patient had thrombocytopenia from grade 0 to 4 , which normalized on repeat assessment.

Elevated creatinine. Mean (SD) serum creatinine (mg/dL) levels 


\begin{tabular}{|c|c|c|}
\hline \multicolumn{3}{|l|}{ Exposure } \\
\hline Patients, $\mathrm{n}$ & 497 & 242 \\
\hline Total patient-yrs & 1764.0 & 817.7 \\
\hline Mean (SD), yrs & $3.55(1.57)$ & $3.38(1.59)$ \\
\hline TEAEs & n (EAIR/100 PYE) & $\mathrm{n}(\mathrm{EAIR} / 100 \mathrm{PYE})$ \\
\hline Any TEAE & $434(24.6)$ & $211(25.8)$ \\
\hline $\begin{array}{l}\text { Any TEAE leading to premature discontinuation } \\
\text { study drug or study }\end{array}$ & $131(7.4)$ & $77(9.4)$ \\
\hline $\begin{array}{l}\text { Any TEAE leading to temporary interruption of } \\
\text { any study drug }\end{array}$ & $111(6.3)$ & $44(5.4)$ \\
\hline Serious TEAE & $54(3.1)$ & $35(4.3)$ \\
\hline Treatment-related TEAE & $242(13.7)$ & $116(14.2)$ \\
\hline Treatment-related serious TEAE ${ }^{a}$ & $9(0.5)$ & $10(1.2)$ \\
\hline Death $^{\mathrm{b}}$ & $3(0.2)$ & $3(0.4)$ \\
\hline \multicolumn{3}{|l|}{ Most common TEAEs ( $\geq 5 \%$ in either treatment group) ${ }^{c}$} \\
\hline Mycobacterium tuberculosis complex test positive & $53(3.0)$ & $38(4.6)$ \\
\hline Upper respiratory tract infection & $52(2.9)$ & $35(4.3)$ \\
\hline Urinary tract infection & $56(3.2)$ & $26(3.2)$ \\
\hline Nasopharyngitis & $56(3.2)$ & $20(2.4)$ \\
\hline Hypertension & $52(2.9)$ & $21(2.6)$ \\
\hline Bronchitis & $51(2.9)$ & $17(2.1)$ \\
\hline Hypercholesterolemia & $36(2.0)$ & $28(3.4)$ \\
\hline Headache & $28(1.6)$ & $26(3.2)$ \\
\hline Dyslipidemia & $32(1.8)$ & $13(1.6)$ \\
\hline Rheumatoid arthritis & $32(1.8)$ & $13(1.6)$ \\
\hline Back pain & $31(1.8)$ & $11(1.3)$ \\
\hline Influenza & $30(1.7)$ & $10(1.2)$ \\
\hline Lymphopenia & $29(1.6)$ & $11(1.3)$ \\
\hline Pharyngitis & $28(1.6)$ & $10(1.2)$ \\
\hline Diarrhea & $28(1.6)$ & $9(1.1)$ \\
\hline Gastroenteritis & $27(1.5)$ & $9(1.1)$ \\
\hline $\mathrm{HZV}$ & $22(4.4)$ & $12(5.0)$ \\
\hline Blood creatinine increased & $11(2.2)$ & $18(7.4)$ \\
\hline Hypertriglyceridemia & $16(3.2)$ & $12(5.0)$ \\
\hline Blood cholesterol increased & $8(1.6)$ & $17(7.0)$ \\
\hline Lymphocyte count decreased & $11(2.2)$ & $14(5.8)$ \\
\hline \multicolumn{3}{|l|}{ Adverse events of special interest $\mathrm{t}^{\mathrm{d}}$} \\
\hline Any infections & $288(16.3)$ & $130(15.9)$ \\
\hline Serious infections & $11(0.6)$ & $14(1.7)$ \\
\hline $\mathrm{HZV}$ & $23(1.3)$ & $12(1.5)$ \\
\hline Malignancy, excluding NMSC ${ }^{e}$ & $9(0.5)$ & $5(0.6)$ \\
\hline NMSC & $6(0.3)$ & $1(0.1)$ \\
\hline $\mathrm{MACE}^{\mathrm{f}}$ & $3(0.2)$ & $2(0.2)$ \\
\hline DVT and/or $P E^{f}$ & $1(0.1)^{g}$ & 0 \\
\hline GI perforation & $1(0.1)^{\mathrm{h}}$ & 0 \\
\hline Active tuberculosis & 0 & 0 \\
\hline
\end{tabular}

${ }^{a}$ Filgotinib + MTX: pneumonia (2), HZV infection (2), asthenia (1), abdominal wall infection (1), breast cancer (1), colon adenoma (1), diffuse large B cell lymphoma (1); filgotinib monotherapy: pneumonia (2), NHL (2); Escherichia urinary tract infection (1), jaw abscess (1), liver hemangioma (1), squamous cell carcinoma (1), spontaneous abortion (1), renal cyst (1). ${ }^{b}$ Filgotinib + MTX: meningococcal meningitis, leiomyosarcoma, DVT/PE; filgotinib monotherapy: pneumonia, NHL (2). ${ }^{\mathrm{c}}$ Occurring in $\geq 5 \%$ of a proportion of patients in either treatment group. ${ }^{\mathrm{d}}$ Includes TEAEs and non-TEAEs. ${ }^{e}$ Of the 13 patients with treatment-emergent malignancies, 4 were hematologic ( 3 NHL and 1 diffuse large B cell lymphoma) and 9 were solid tumors ( 2 lung cancer, 2 breast cancer, 1 each colon cancer, gallbladder adenocarcinoma, metastatic leiomyosarcoma, melanoma, and renal cancer). ${ }^{\mathrm{f}}$ Positively adjudicated events. ${ }^{\mathrm{g}}$ Patient had simultaneous DVT and PE. ${ }^{\mathrm{h}}$ Procedural small bowel perforation. AE: adverse event; DVT: deep vein thrombosis; EAIR: exposure-adjusted incidence rate; GI: gastrointestinal; HZV: herpes zoster virus; MACE: major adverse cardiovascular event; MTX: methotrexate; NHL: non-Hodgkin lymphoma; NMSC: nonmelanoma skin cancer; PE: pulmonary embolism; PYE: patient-years of exposure; TEAE: treatment-emergent adverse event. 
Table 3. Treatment-emergent laboratory abnormalities through April 2019 data cut.

Filgotinib + MTX, Filgotinib Monotherapy, $\mathrm{n}=497 \quad \mathrm{n}=242$

Patients With Postbaseline

Value, $\mathrm{n}$ 496 242

Anemia Grade 1

Grade 2

Grade 3

Grade 4

Neutropenia

Grade 1

Grade 2

Grade 3

Grade 4

Lymphopenia

Grade 1

Grade 2

Grade 3

Grade 4

Leukopenia

Grade 1

Grade 2

Grade 3

Grade 4

Thrombocytopenia

Grade 1

Grade 2

Grade 3

Grade 4

Cr elevation

Grade 1

Grade 2

Grade 3

Grade 4

Cholesterol, fasting (increased)

$\begin{array}{ccc}\text { Grade } 1 & 196(43.3) & 93(43.7) \\ \text { Grade } 2 & 51(11.3) & 36(16.9) \\ \text { Grade 3 } & 3(0.7) & 1(0.5) \\ \text { Grade 4 } & 0(0) & 0(0)\end{array}$

ALT elevation

Grade 1

Grade 2

$131(26.4)$

$14(2.8)$

$4(0.8)$

$0(0)$

$54(22.3)$

Grade 3

Grade 4

AST elevation

Grade 1

$139(28.0)$

$10(2.0)$

$1(0.2)$

Grade 3

$0(0)$

$2(0.8)$

$1(0.4)$

$0(0)$

Grade 4

Values are n (\%) unless otherwise indicated. For each individual laboratory test, the most severe graded abnormality for that test was counted for a patient. a Severity grades were defined as: Grade 1 (> ULN-300 mg/ $\mathrm{dL}[7.75 \mathrm{mmol} / \mathrm{L}])$, Grade 2 (> 300-400 mg/dL [7.75-10.34 mmol/L]), Grade 3 (> 400-500 mg/dL [10.34-12.92 mmol/L]), Grade 4 (> 500 mg/ $\mathrm{dL}[12.92 \mathrm{mmol} / \mathrm{L}])$. ALT: alanine aminotransferase; AST: aspartate aminotransferase; $\mathrm{Cr}$ : creatinine; MTX: methotrexate; NA: not applicable; ULN: upper limit of normal. were $0.68(0.15)$ and $0.69(0.17)$ at baseline, and $0.79(0.17)$ and $0.79(0.17)$ at Week 204 in the filgotinib + MTX and filgotinib monotherapy groups, respectively. One patient in the filgotinib + MTX group experienced an increase to grade 3 through Week 204, which normalized over 4 months, during which filgotinib was withheld for 12 days.

Hyperlipidemia. Mean (SD) total cholesterol levels (mg/dL) were 191 (40) and 196 (41) at baseline, and 212 (47) and 225 (42) at Week 204 in the filgotinib + MTX and filgotinib monotherapy groups, respectively. Eighteen and 14 patients had an increase in severity from desirable to high in the filgotinib + MTX and filgotinib monotherapy groups, respectively, through Week 204. Twenty-three and 14 patients had an increase in low-density lipoprotein/high-density lipoprotein severity from optimal to high in the filgotinib + MTX and filgotinib monotherapy groups, respectively, through Week 204. Twenty-two patients had an increase from optimal to high multiple times through Week 204.

Aspartate aminotransferase and alanine aminotransferase elevation. Mean (SD) values (U/L) for aspartate aminotransferase (AST)/alanine aminotransferase (ALT) were 20 (9)/18 (12) and $19(9) / 17(11)$ at baseline, and $26(15) / 24$ (17) and 25 (9)/22 (14) at Week 204, for the filgotinib + MTX and filgotinib monotherapy groups, respectively. Six patients (1 filgotinib monotherapy and 5 filgotinib + MTX) had an increase in AST or ALT to > 5-10× ULN from normal baseline values through Week 204: 4 normalized on repeat assessment without medication changes, 1 exited the study, and 1 continued to have fluctuations.

Efficacy. At Week 204, ACR20/50/70 responses were $89.3 \% / 69.6 \% / 49.1 \%$ and $91.8 \% / 69.4 \% / 44.4 \%$ in the filgotinib + MTX and filgotinib monotherapy groups, respectively, based on the "as observed" analysis. The ACR20/50/70 responses increased from baseline through Week 96 and remained stable thereafter. The remission rates, defined as Disease Activity in 28 joints based on CRP < 2.6 at Week 204, were $57.5 \%$ and $49.6 \%$ for the filgotinib + MTX and filgotinib monotherapy groups, respectively, and were maintained through Week 204 (Figure 2). NRI analysis followed a similar pattern of response, with lower overall response rates (Supplementary Figure 3, available with the online version of this article). Changes in other efficacy measures are listed in Supplementary Table 3.

\section{DISCUSSION}

The data from DARWIN 3 with a mean (SD) of 3.5 (1.6) years of filgotinib treatment and 2582 PYE demonstrates long-term safety, tolerability, and sustained response to filgotinib either in combination with MTX or as monotherapy in patients with moderately to severely active RA and an inadequate response to MTX. There were no meaningful safety differences between patients receiving filgotinib $200 \mathrm{mg}$ as monotherapy or in combination with MTX. In this longest observational data on filgotinib to date, no additional safety signals were identified within these RA populations treated with filgotinib. ${ }^{13,14,15} \mathrm{~A}$ positive Mycobacterium tuberculosis test and latent TB, both protocol-mandated criteria for discontinuation, were among 

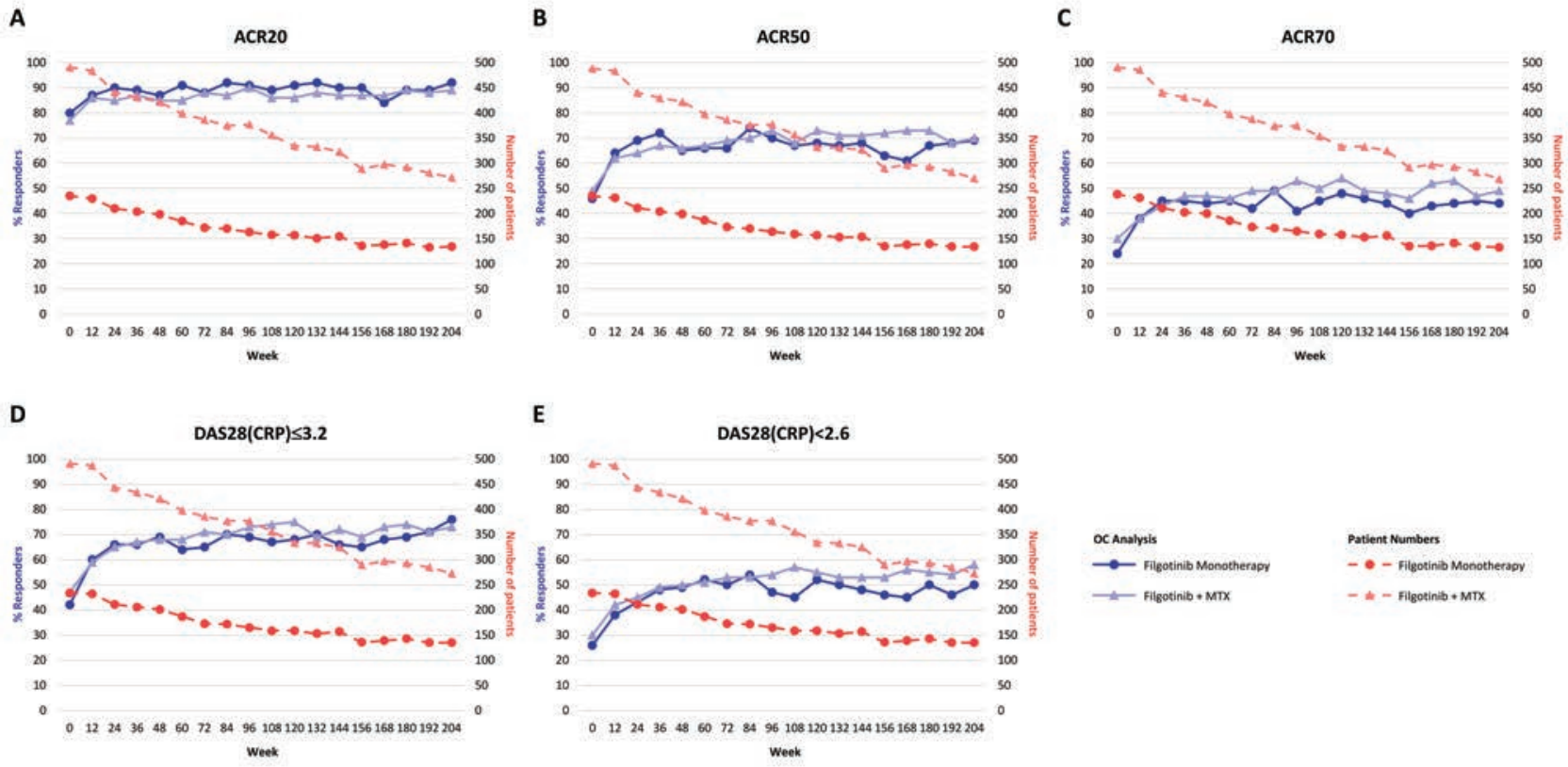

Figure 2. Efficacy variables in patients receiving filgotinib monotherapy or filgotinib + MTX using observed case analysis. (A) ACR20 response rates; (B) ACR50 response rates; and (C) ACR70 response rates; (D) DAS28(CRP) $\leq 3.2$ response rates; and (E) DAS28(CRP) < 2.6 response rates. Percent responders are relative to baseline in parent study. ACR: American College of Rheumatology; DAS28(CRP): Disease Activity Score in 28 joints based on C-reactive protein; MTX: methotrexate; OC: observed case.

the most common AEs leading to discontinuation. The high enrollment in regions where $\mathrm{TB}$ is prevalent, along with a switch to a more sensitive QuantiFERON-TB Gold assay, may have contributed to higher-than-expected rates of positive TB tests (Table 1). In addition, improved disease control later during the study, with presumably less anergy, may have resulted in more positive QuantiFERON-TB Gold assay results. Last, with longer follow-up, it is expected that patients will have increased risk for exposure and new infections. No active TB cases were reported.

Patients with RA have an increased risk of HZV infection compared with the general population. ${ }^{16,17,18}$ A metaanalysis of phase II and III randomized controlled trials for JAK inhibitors reported incidence rates for $\mathrm{HZV}$ infection that were higher than expected in the RA population. ${ }^{19}$ The incidence rates of HZV infections in this study were relatively low (1.3 and 1.5 per 100 PYE in the filgotinib + MTX and monotherapy groups, respectively) and similar in patients with and without lymphopenia. While the exact causes of HZV reactivation have not yet been fully elucidated, suppression of cell-mediated immunity by drugs such as corticosteroids has been postulated to play a role in patients with RA. ${ }^{20}$ Additionally, the risk of viral infections, such as HZV reactivation, might be associated with JAK1- and JAK3-mediated intracellular signaling and survival of immune cells and cytokines relevant to HZV control. ${ }^{21}$ Although HZV reactivation appears to be a class effect, some emerging data suggest that there may be relative differences among the various JAK inhibitors regarding the risk of $\mathrm{HZV}^{22,23}$ However, additional data (e.g., from head-to-head studies) are needed to draw any conclusions regarding potential differences in the risk of HZV infection between filgotinib and other JAK inhibitors.

Studies have shown that the risk for malignancies in patients with RA is increased, especially in those on immunosuppressive therapy, compared with the general population. ${ }^{24}$ The incidence rates for malignancy (excluding NMSC) were 0.5 and 0.6 per 100 PYE in the filgotinib + MTX and monotherapy groups, respectively, and were similar to those reported for other JAK inhibitors ${ }^{25,26}$ and bDMARDs. ${ }^{27,28}$

Patients with RA have a 2- to 3-fold increased risk of DVT and $\mathrm{PE}$ compared to the general population, with reported incidence rates ranging from 0.3 to 0.8 per 100 PYE..$^{29,30}$ One patient (on filgotinib + MTX) experienced simultaneous DVT and PE 62 days after the last dose of filgotinib (0.1 per 100 PYE), which was fatal. The number of DVT/PE events from DARWIN 3 was small and appears comparable to the background risk observed in patients with RA. Although incompletely understood, some observational data suggest that the increased risk for DVT/ PE may be a class effect for JAK inhibitors. ${ }^{31}$ Additional data, including long-term postmarketing observational studies, are needed to quantify the risk associated with JAK inhibitors, including filgotinib.

The risk of $\mathrm{CV}$ disease is also increased among patients with RA. ${ }^{32}$ The incidence rates for MACE in this study were low (0.2 per 100 PYE in both groups), and comparable with rates reported for other JAK inhibitors ${ }^{26,33}$ and tumor necrosis factor inhibitors ${ }^{34,35,36}$ in RA.

There was no evidence of progressive worsening of laboratory abnormalities over time. A small percentage of patients experienced an increase in severity from baseline, most from grade $0-1$, with few experiencing an increase to grade $\geq 3$ through 4 years. The majority of grade 3 and 4 changes were transient and normalized without intervention and/or with resolution of concurrent 
illness. Mean $\mathrm{Hb}$, neutrophil, lymphocyte, and platelet counts remained relatively stable over 4 years in both treatment groups. Creatine phosphokinase levels were not monitored during the study. Overall, these results were not unexpected given prior studies suggesting the role of JAK2 inhibition on hematopoiesis and erythropoiesis. ${ }^{37}$ Additional data are needed to fully understand the effect of preferential JAK targeting on changes in biochemistry measures.

Limitations of LTE data analysis include potential bias related to open-label design and inclusion of patients who are more likely to have responded to and tolerated filgotinib. In this study, the majority of the patients from parent studies $(83 \%$ DARWIN 1 and 85\% DARWIN 2) entered the LTE with $>50 \%$ remaining through 4 years. Also, analyses related to infections as a function of leukocyte and lymphocyte counts were of patients with a history of leukopenia or lymphopenia during the study and not necessarily at time of infection. A full assessment of the effect of leukopenia and lymphopenia on infections will be further explored in the integrated safety analysis of filgotinib.

This analysis conducted for up to 4 years of filgotinib exposure demonstrated a consistent safety profile and sustained efficacy for filgotinib when administered as $200 \mathrm{mg}$ daily either alone or in combination with MTX.

\section{ACKNOWLEDGMENT}

We extend our thanks to the patients, their families, and all participating investigators. Editorial support was provided by Impact Communication Partners (New York, NY), which was funded by Gilead Sciences Inc.

\section{ONLINE SUPPLEMENT}

Supplementary material accompanies the online version of this article.

\section{REFERENCES}

1. Singh JA, Saag KG, Bridges SL Jr, Akl EA, Bannuru RR, Sullivan MC, et al. 2015 American College of Rheumatology guideline for the treatment of rheumatoid arthritis. Arthritis Rheumatol 2016;68:1-26.

2. Smolen JS, Landewé RBM, Bijlsma JWJ, Burmester GR, Dougados $\mathrm{M}$, Kerschbaumer A, et al. EULAR recommendations for the management of rheumatoid arthritis with synthetic and biological disease-modifying antirheumatic drugs: 2019 update. Ann Rheum Dis 2020;79:685-99.

3. Ramiro S, Sepriano A, Chatzidionysiou K, Nam JL, Smolen JS, van der Heijde D, et al. Safety of synthetic and biological DMARDs: a systematic literature review informing the 2016 update of the EULAR recommendations for management of rheumatoid arthritis. Ann Rheum Dis 2017;76:1101-36.

4. Furst DE. The risk of infections with biologic therapies for rheumatoid arthritis. Semin Arthritis Rheum 2010;39:327-46.

5. Xeljanz [package insert]. New York, NY: Pfizer Inc. [Internet. Accessed April 27, 2021.] Available from: http://labeling.pfizer. com/showlabeling.aspx $?$ id $=959$

6. Pfizer Limited. Summary of Product Characteristics: Xeljanz $5 \mathrm{mg}$ film-coated tablets. [Internet. Accessed April 27, 2021.] Available from: https://www.medicines.org.uk/emc/product/2500/smpc

7. Japan Ministry of Health Labour and Welfare. Report of the deliberation results, Xeljanz tablets $5 \mathrm{mg}$. [Internet. Accessed April 27, 2021.] Available from: https://www.pmda.go.jp/ files/000153609.pdf

8. Eli Lilly and Company Limited. Summary of product characteristics:
Olumiant $2 \mathrm{mg}$ film-coated tablets [Internet. Accessed April 27, 2021.] Available from: https://www.medicines.org.uk/emc/ product $/ 2434 / \mathrm{smpc}$

9. Korea Biomedical Review. Korea approves Olumiant pills for treatment of rheumatoid arthritis. [Internet. Accessed April 27, 2021.] Available from: http://www.koreabiomed.com/news/ articleView.html?idxno $=2098$

10. Rinvoq [package insert]. North Chicago, IL: AbbVie Inc. [Internet. Accessed April 27, 2021.] https://www.rxabbvie.com/pdf/ rinvoq_pi.pdf

11. Kavanaugh A, Kremer J, Ponce L, Cseuz R, Reshetko OV, Stanislavchuk M, et al. Filgotinib (GLPG0634/GS-6034), an oral selective JAK1 inhibitor, is effective as monotherapy in patients with active rheumatoid arthritis: results from a randomised, dose-finding study (DARWIN 2). Ann Rheum Dis 2017;76:1009-19.

12. Westhovens R, Taylor PC, Alten R, Pavlova D, Enríquez-Sosa F, Mazur M, et al. Filgotinib (GLPG0634/GS-6034), an oral JAK1 selective inhibitor, is effective in combination with methotrexate (MTX) in patients with active rheumatoid arthritis and insufficient response to MTX: results from a randomised, dose-finding study (DARWIN 1). Ann Rheum Dis 2017;76:998-1008.

13. Genovese MC, Kalunian K, Gottenberg JE, Mozaffarian N, Bartok B, Matzkies F, et al. Effect of filgotinib vs placebo on clinical response in patients with moderate to severe rheumatoid arthritis refractory to disease-modifying antirheumatic drug therapy: the FINCH 2 randomized clinical trial. JAMA 2019;322:315-25.

14. Combe B, Kivitz A, Tanaka Y, van der Heijde D, Matzkies F, Bartok B, et al. Efficacy and safety of filgotinib for patients with rheumatoid arthritis with inadequate response to methotrexate: FINCH1 primary outcome results [abstract]. Arthritis Rheumatol 2019;71 Suppl 10.

15. Genovese MC, Kalunian KC, Walker D, Gottenberg JE, de Vlam $\mathrm{K}$, Mozaffarian N, et al. Safety and efficacy of filgotinib in a phase 3 trial of patients with active rheumatoid arthritis and inadequate response or intolerance to biologic DMARDs [abstract]. Arthritis Rheumatol 2018;70 Suppl 10.

16. Smitten AL, Choi HK, Hochberg MC, Suissa S, Simon TA, Testa MA, et al. The risk of herpes zoster in patients with rheumatoid arthritis in the United States and the United Kingdom. Arthritis Rheum 2007;57:1431-8.

17. Veetil BMA, Myasoedova E, Matteson EL, Gabriel SE, Green $\mathrm{AB}$, Crowson CS. Incidence and time trends of herpes zoster in rheumatoid arthritis: a population-based cohort study. Arthritis Care Res 2013;65:854-61.

18. Widdifield J, Bernatsky S, Paterson JM, Gunraj N, Thorne JC, Pope $\mathrm{J}$, et al. Serious infections in a population-based cohort of 86,039 seniors with rheumatoid arthritis. Arthritis Care Res 2013; 65:353-61.

19. Bechman K, Subesinghe S, Norton S, Atzeni F, Galli M, Cope AP, et al. A systematic review and meta-analysis of infection risk with small molecule JAK inhibitors in rheumatoid arthritis. Rheumatology 2019;58:1755-66.

20. Harpaz R, Ortega-Sanchez IR, Seward JF. Prevention of herpes zoster: recommendations of the Advisory Committee on Immunization Practices (ACIP). MMWR Recomm Rep 2008; 57:1-30.

21. Sunzini F, McInnes I, Siebert S. JAK inhibitors and infections risk: focus on herpes zoster. Ther Adv Musculoskelet Dis 2020;12:1759720X20936059.

22. Curtis JR, Xie F, Yun H, Bernatsky S, Winthrop KL. Real-world comparative risks of herpes virus infections in tofacitinib and biologic-treated patients with rheumatoid arthritis. Ann Rheum Dis 2016;75:1843-7.

23. Harigai M, Honda S. Selectivity of Janus kinase inhibitors in 
rheumatoid arthritis and other immune-mediated inflammatory diseases: is expectation the root of all headache? Drugs 2020;80:1183-1201.

24. Simon TA, Thompson A, Gandhi KK, Hochberg MC, Suissa S. Incidence of malignancy in adult patients with rheumatoid arthritis: a meta-analysis. Arthritis Res Ther 2015;17:212.

25. Cohen SB, Tanaka Y, Mariette X, Curtis JR, Lee EB, Nash P, et al. Long-term safety of tofacitinib for the treatment of rheumatoid arthritis up to 8.5 years: integrated analysis of data from the global clinical trials. Ann Rheum Dis 2017;76:1253-62.

26. Genovese M, Smolen J, Takeuchi T, Burmester GR, Brinker D, Rooney T, et al. Safety profile of baricitinib for the treatment of rheumatoid arthritis up to 7 years: an updated integrated safety analysis [abstract]. Arthritis Rheumatol 2019;71 Suppl 10.

27. Burmester GR, Gordon KB, Rosenbaum JT, Arikan D, Lau WL, Li $P$, et al. Long-term safety of adalimumab in 29,967 adult patients from global clinical trials across multiple indications: an updated analysis. Adv Ther 2020;37:364-80.

28. Weinblatt ME, Moreland LW, Westhovens R, Cohen RB, Kelly SM, Khan N, et al. Safety of abatacept administered intravenously in treatment of rheumatoid arthritis: integrated analyses of up to 8 years of treatment from the abatacept clinical trial program. J Rheumatol 2013;40:787-97.

29. Kim SC, Schneeweiss S, Liu J, Solomon DH. Risk of venous thromboembolism in patients with rheumatoid arthritis. Arthritis Care Res 2013;65:1600-7.

30. Ogdie A, Mcgill NK, Shin DB, Takeshita J, Love TJ, Noe MH, et al. Risk of venous thromboembolism in patients with psoriatic arthritis, psoriasis and rheumatoid arthritis: a general population-based cohort study. Eur Heart J 2018;39:3608-14.
31. Verden A, Dimbil M, Kyle R, Overstreet B, Hoffman KB. Analysis of spontaneous postmarket case reports submitted to the FDA regarding thromboembolic adverse events and JAK inhibitors. Drug Saf 2018; $41: 357-61$

32. Avina-Zubieta JA, Thomas J, Sadatsafavi M, Lehman AJ, Lacaille D. Risk of incident cardiovascular events in patients with rheumatoid arthritis: a meta-analysis of observational studies. Ann Rheum Dis 2012;71:1524-9.

33. Charles-Schoeman C, Wicker P, Gonzalez-Gay MA, Boy M, Zuckerman A, Soma K, et al. Cardiovascular safety findings in patients with rheumatoid arthritis treated with tofacitinib, an oral Janus kinase inhibitor. Semin Arthritis Rheum 2016;46:261-71.

34. Jacobsson LT, Turesson C, Gülfe A, Kapetanovic MC, Petersson IF, Saxne T, et al. Treatment with tumor necrosis factor blockers is associated with a lower incidence of first cardiovascular events in patients with rheumatoid arthritis. J Rheumatol 2005;32:1213-8.

35. Dixon WG, Watson KD, Lunt M, Hyrich KL, British Society for Rheumatology Biologics Register Control Centre Consortium, et al. Reduction in the incidence of myocardial infarction in patients with rheumatoid arthritis who respond to anti-tumor necrosis factor alpha therapy: results from the British Society for Rheumatology Biologics Register. Arthritis Rheum 2007;56:2905-12.

36. Ljung L, Rantapää-Dahlqvist S, Jacobsson LT, Askling J. Response to biological treatment and subsequent risk of coronary events in rheumatoid arthritis. Ann Rheum Dis 2016;75:2087-94.

37. Choy EH. Clinical significance of Janus kinase inhibitor selectivity. Rheumatology 2019;58:953-62. 